\title{
PersistênCia dos Herbicidas Imazethapyr e Imazapic em Solo de VÁRzea sob Diferentes Sistemas de Manejo ${ }^{1}$
}

\author{
Persistence of the Herbicides Imazethapyr and Imazapic in Irrigated Rice Soil \\ KRAEMER, A.F..$^{2}$, MARCHESAN, E. ${ }^{3}$, AVILA, L.A. ${ }^{3}$, MACHADO, S.L.O. ${ }^{3}$, GROHS, M. ${ }^{5}$, \\ MASSONI, P.F.S. ${ }^{5}$ e SARTORI, G.M.S. ${ }^{5}$
}

\begin{abstract}
RESUMO - A mistura formulada dos herbicidas imazethapyr e imazapic é utilizada para controlar arroz-vermelho em cultivos de arroz irrigado. Entretanto, esses herbicidas podem persistir no solo por longos períodos, causando introxicação ao arroz suscetivel cultivado em sucessão. Este trabalho teve como objetivo avaliar o efeito de diferentes manejos de solo, durante a entressafra do arroz, sobre a ação residual do imazethapyr e imazapic, em arroz não tolerante. O residual desses herbicidas causou introxicação no arroz suscetivel após um ano da última aplicação dos herbicidas. A introxicação atingiu valores máximos até 25 dias após a emergência (DAE), ocorrendo redução da introxicação após esse período, até praticamente desaparecer (60 DAE). O residual do herbicida alterou o estande de plantas, o número de colmos $\mathrm{m}^{-2}$, o número de panículas $\mathrm{m}^{-2}$ e a altura de plantas, porém não afetou a produtividade de grãos do arroz. O revolvimento do solo diminuiu a atividade do herbicida na camada superficial de solo $(0-3 \mathrm{~m})$.
\end{abstract}

Palavras-chave: residual de herbicida, imidazolinonas, preparo de solo.

\begin{abstract}
The mixture of herbicides imazethapyr and imazapic is used to control red rice in irrigated rice crops. However, such herbicides might persist on the soil for a long period causing phytotoxicity on susceptible rice grown in succession. The objective of this work was to determine the effect of different soil tillage systems during the off-season on the residual phytotoxicity of imazethapyr and imazapic on non tolerant rice. Herbicide residues caused phytotoxicity on susceptible rice with the highest values being registered 25 days after emergence and decreasing after this period until almost disappearing 60 days after emergence. Herbicide residues affected plant stand, number of stems per $m^{2}$, number of panicles per $m^{2}$ and plant height, but did not affect grain yield. Soil movement decreased herbicide activity on the superficial soil layer $(0-3 \mathrm{~cm})$.
\end{abstract}

Keywords: herbicide residues, imidazolinonas, soil tillage.

\section{INTRODUÇÃO}

Os herbicidas imazethapyr e imazapic pertencem à familia das imidazolinonas e controlam um amplo espectro de plantas daninhas, incluindo gramíneas, ciperáceas e dicotiledôneas. São absorvidos por raizes e folhas, sendo translocados por floema e xilema, acumulando-se nos pontos de crescimento.
O controle é proporcionado pela inibição da enzima acetolactase sintetase (ALS), que é essencial no processo de síntese de aminoácidos de cadeia ramificada em plantas isoleusina, leusina e valina (Tan et al., 2006). Atualmente, esses herbicidas são comercializados em mistura formulada para controle de plantas daninhas em arroz. A tolerância foi obtida por mutações induzidas, utilizando-se

1 Recebido para publicação em 15.3.2008 e na forma revisada em 15.5.2009.

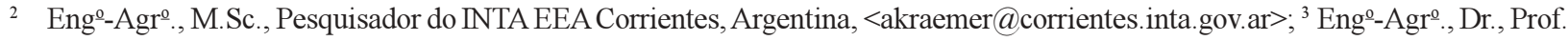
do Dep. de Fitotecnia, Universidade Federal de Santa Maria - UFSM, ${ }^{4}$ Eng ${ }^{0}$-Agr ${ }^{\circ}$., Dr.., Prof. do Dep. de Defesa Fitossanitária UFSM.; ${ }^{5}$ Acadêmico/a do curso de Agronomia, Dep. de Fitotecnia - UFSM, Santa Maria-RS, Brasil. 
tratamento das sementes com químicos mutagênicos, a etil metanosulfonato (EMS), ou radiação gama (Croughan, 1998).

Essa tecnologia foi introduzida como opção para ajudar a solucionar o principal problema das lavouras de arroz do RS, permitindo o controle químico eficiente do arroz-vermelho (Villa et al., 2006; Santos et al., 2006). No entanto, os herbicidas podem persistir no solo após o cultivo, em quantidade que pode comprometer a utilização futura da área com outras culturas suscetiveis, ou mesmo com cultivares de arroz não tolerante.

Os danos causados às culturas em sucessão são variáveis, dependendo das condições físicas, químicas e de manejo do solo. Foram encontrados prejuízos por introxicação devido ao residual de imazethapyr e imazapic isolados ou à associação de ambos em diferentes culturas: alfafa, algodão, aveia, azevém, batata, beterraba-açucareira, canola, cebola, ervilha, girassol, linho, melão, milho, mostarda, pimenta, pimentão, repolho, sorgo, trigo e tomate (Bovey \& Senseman, 1998; Alister \& Kogan 2005).

Em arroz não tolerante, Villa al. (2006) constataram menor estande de plantas por efeito residual da associação imazethapyr + imazapic, porém sem efeito na produtividade. Nesse sentido, Zhang et al. (2000) também constataram diminuição na produtividade de arroz não tolerante de $69 \%$ pelo efeito residual de imazethapyr. Williams et al. (2002) recomendam o tempo de 540 dias (18 meses) entre a aplicação de imazethapyr e a semeadura de arroz não tolerante para não haver risco de ocorrência de sintomas de introxicação.

Para diminuir esses problemas na cultura do arroz, preconiza-se o uso dessa tecnologia por não mais de dois anos consecutivos, deixando a área em pousio por, no mínimo, um ano. A persistência do herbicida no solo depende das condições climáticas, das propriedades do solo e da quantidade desse herbicida. O principal mecanismo de dissipação das imidazolinonas no solo é a degradação microbiana (Loux \& Reese, 1993; Flint, \& Witt, 1997). Para imazethapyr, a dissipação acontece exclusivamente em condições de aerobiose (Shaner \& O`Connor, 1991). Esses herbicidas também sofrem fotólise, podendo ser esse meio de dissipação relevante em solo arenoso e úmido, e não em outros tipos de solo (Curran et al., 1992a). Esses processos ficam regulados pela sorção das moléculas dos herbicidas aos coloides do solo e pelas condições ambientais que favoreçam o desenvolvimento dos microrganismos.

Em solos com $\mathrm{pH}$ baixo ocorre maior adsorção desses herbicidas e menor biodegradação (Bresnaham et al., 2000; Madani et al., 2003; Fernandes de Oliveira et al., 2004), porque a sorção determina quanto do herbicida vai ficar retido na matriz do solo e quanto ficará disponivel na solução deste para sofrer os diferentes processos de dissipação. Os solos arrozeiros do RS são predominantemente ácidos, e 50\% desses apresentam $\mathrm{pH}$ inferior a 5 (Anghinoni et al., 2004). Nessas condições, os herbicidas imazethapyr e imazapic têm alta probabilidade de permanecer adsorvidos ao solo, aumentando sua persistência e o risco de efeitos sobre culturas em sucessão. Há evidências sugerindo que a utilização de práticas de manejo que estimulem a degradação de herbicidas no solo durante o período da entressafra do arroz pode reduzir a persistência destes, minimizando os danos aos cultivos subsequentes. Isso porque os processos biológicos estariam sendo influenciados por fatores ambientais, como umidade, temperatura e aeração, os quais estão relacionados às práticas de preparo do solo (Soon \& Arshad, 2005; Perez et al., 2005); o preparo do solo pode aumentar em $57 \%$ a atividade microbiana (Franchini et al., 2007).

Em vista do exposto, o presente trabalho teve por objetivo determinar o efeito de diferentes manejos do solo, durante o período de entressafra do arroz, sobre a minimização dos efeitos residuais da associação dos herbicidas imazethapyr + imazapic, na cultura do arroz não tolerante.

\section{MATERIAL E MÉTODOS}

No ano agrícola 2006/07 foram realizados seis experimentos: um experimento testando o efeito de diferentes manejos de solo na persistência de imazethapyr e imazapic; quatro experimentos para comparar os cultivares IRGA 422CL e IRGA 417; e um 
bioensaio para determinar a presença desses herbicidas, utilizando como planta indicadora o tomate.

O experimento com os diferentes manejos de solo foi realizado em área que havia recebido $1 \mathrm{~L} \mathrm{ha}^{-1}$ ano $^{-1}$ da mistura formulada de imazethapyr + imazapic $\left(75+25 \mathrm{~g} \mathrm{~L}^{-1}\right)$ nas safras de 2004/05 e 2005/06. O solo, classificado como Planossolo Hidromórfico eutrófico arênico, apresentava as seguintes características: $\mathrm{pH}_{\text {água }}(1: 1)=4,8 ; \quad \mathrm{P}=$ $6,0 \mathrm{mg} \mathrm{dm}^{-3} ; \mathrm{K}=120 \mathrm{mg} \mathrm{dm}^{-3} ;$ argila $=26 \%$; $\mathrm{MO}=2,3 \% ; \mathrm{Ca}=5,0 \mathrm{cmol}_{\mathrm{c}} \mathrm{dm}^{-3} ; \mathrm{Mg}=$ $2,0 \mathrm{cmol}_{\mathrm{c}} \mathrm{dm}^{-3} ; \mathrm{Al}=1,7 \mathrm{cmol}_{\mathrm{c}} \mathrm{dm}^{-3} ;$ e índice SMP de 5,1. O delineamento experimental foi de blocos ao acaso em esquema fatorial, com quatro repetições. Os tratamentos consistiram da combinação de nove manejos de solo e de dois cultivares de arroz irrigado. Os manejos de solo foram quatro nos sistemas de plantio direto e semidireto e cinco no sistema plantio convencional: plantio direto (PD); plantio direto com azevém (PDA); um preparo de solo em abril (1PSA); um preparo de solo em abril com azevém (1PSAA); um preparo de solo em outubro (1PSO); dois preparos de solo, em maio e outubro (2PSMO); dois preparos de solo, em abril e outubro (2PS); três preparos de solo, em abril, maio e outubro (3PS); e quatro preparos de solo, em abril, maio, agosto e outubro (4PS). Os cultivares de arroz testados foram IRGA 422CL e IRGA 417. As datas de semeadura e emergência foram 4/10/2007 e 16/10/07, respectivamente, para os dois cultivares.

O cultivar IRGA 422CL, por ser tolerante a herbicidas do grupo das imidazolinonas e possuir características agronômicas semelhantes às do cultivar suscetivel IRGA 417 (Lopes et al., 2003), foi utilizado como testemunha, pois a área experimental não contava com unidades experimentais sem aplicação prévia do herbicida. Para ratificar a similaridade entre os cultivares, foram semeados quatro experimentos comparativos, em diferentes áreas onde não havia resíduos no solo de imidazolinonas, em delineamento inteiramente casualizado com dois tratamentos, constituídos pelos cultivares IRGA 422CL e IRGA 417, em seis repetições cada um. A análise dos dados desses experimentos foi feita de forma conjunta.
Nos cinco experimentos utilizaram-se $110 \mathrm{~kg}$ de sementes ha-1, para os dois cultivares, com semeadora de 11 linhas espaçadas de $0,175 \mathrm{~m}$ e 5,0 $\mathrm{m}$ de comprimento, gerando uma unidade experimental (UE) de 9,6 $\mathrm{m}^{2}$. As práticas agronômicas foram as mesmas nos cinco experimentos, conforme as recomendações da pesquisa para obtenção de alto rendimento (SOSBAI, 2005). Em todas as unidades experimentais foram demarcadas, em duas linhas de semeadura, 1,0 m em cada uma, onde se determinou o estande inicial de plantas, aos 10 e 17 dias após emergência (DAE), o número de colmos aos $60 \mathrm{DAE}$ e o número de panículas aos 110 DAE. Na mesma área, aos $110 \mathrm{DAE}$, avaliou-se a altura de dez plantas escolhidas ao acaso, aferindo-se o comprimento desde o solo até o ápice da panícula. Ainda nesse local, simultaneamente, coletaram-se dez panículas consecutivas escolhidas ao acaso, das quais foram determinados o número de grãos por panícula, a esterilidade de espiguetas e a massa de mil grãos.

A produtividade de grãos foi obtida pela colheita manual, de sete linhas centrais, quando os grãos apresentavam umidade média de $20 \%$. Após a trilha, limpeza e pesagem dos grãos com casca, os dados foram corrigidos para $13 \%$ de umidade e convertidos em $\mathrm{kg} \mathrm{ha}^{-1}$. Foram feitas avaliações de introxicação no arroz não tolerante (IRGA 417) aos 10, 17, 24, 36 e $59 \mathrm{DAE}$, sendo os valores estimados visualmente, utilizando uma escala de 0 a $100 \%$, em que 0 representou ausência de introxicação das plantas e 100 a morte das plantas. Estas avaliações não foram feitas no cultivar tolerante, por este não apresentar sintomas de introxicação, o que ocasionaria aumento da variabilidade e não somaria informação ao trabalho. Para os dados de introxicação, o experimento foi o de blocos ao acaso.

Por último, foi semeado um bioensaio, onde foi utilizado como planta indicadora da atividade do herbicida o tomate (Rampelotti et al., 2005), semeando-se seis sementes por vaso de $250 \mathrm{~mL}$, deixando três plantas, que constituíram a UE. Os vasos foram preenchidos com amostras de solo coletadas dos manejos PD, 4PS e pousio (solo coletado de uma área deixada em pousio sem inundação). As amostras foram coletadas a duas profundidades $(0-3$ e 3-6 cm), após a colheita do experimento de 
manejos de solo. O delineamento foi inteiramente casualizado, em esquema fatorial $3 \times 2$, com seis repetições. Os tratamentos consistiram da combinação dos três manejos de solo com as duas profundidades. Foi determinada a introxicação das plantas de tomate, utilizando a escala de 0 a $100 \%$ aos 20 DAE dessas plantas.

Os dados foram submetidos à análise de variância e as médias comparadas pelo teste de Tukey $(\mathrm{P} \leq 0,05)$. Para a análise estatística, os dados de introxicação foram transformados para $y t=\operatorname{arcsen} o \sqrt{(y+0,5) / 100}$, e os demais dados em porcentagem foram transformados para $\mathrm{yt}=\sqrt{\mathrm{y}+1}$.

\section{RESULTADOS E DISCUSSÃO}

No experimento preliminar, comparando os cultivares IRGA 422CL e IRGA 417, não foram encontradas diferenças entre eles quanto a produtividade de grãos e parâmetros agronômicos (Tabela 1), estando de acordo com relatos de Lopes et al. (2003). Com base nesses resultados, o cultivar IRGA 422CL foi utilizado como testemunha, tornando possivel avaliar o efeito residual da associação dos herbicidas imazethapyr + imazapic.

Ocorreu redução dos sintomas de introxicação das plantas de arroz do cultivar IRGA 417 com a mistura dos herbicidas no transcorrer do desenvolvimento das plantas, observandose os maiores valores até os 24 dias após a emergência (DAE) da cultura (valores médios entre os diferentes manejos de solo de $28 \%$, diminuindo aos $36 \mathrm{DAE}$ para $9 \%$, até praticamente desaparecer aos $59 \mathrm{DAE}$ ). Observou-se, também, redução das diferenças entre os preparos de solo a partir de $36 \mathrm{DAE}$ (Figura 1). $\mathrm{Na}$ mesma figura, pode-se agrupar o efeito residual no solo do herbicida em três grupos de preparos de solo. O tratamento 1PSO apresentou as maiores porcentagens de introxicação, enquanto os valores intermediários pertenceram aos outros tratamentos com plantio convencional (4PS, 3PS, 2PS e 2PSMO); menor introxicação foi encontrada nos tratamentos com plantio direto ou semidireto (PD, PDA, 1PSA e 1PSAA).

Esses resultados diferem de outros trabalhos realizados em solos com culturas de sequeiro, em que se observou que o preparo de solo acelerava ou não alterava a degradação das imidazolinonas. Nesse sentido, Curran et al. (1992b) encontraram maior efeito residual no solo de imazaquin e imazethapyr em milho semeado no sistema de PD do que no plantio convencional. Todavia, Monks \& Banks (1993) não observaram efeito de diferentes manejos de palha e de preparo de solo no residual de imazaquin e imazethapyr, enquanto Renner et al. (1998), compararando o efeito de diferentes sistemas de preparo de solo na dissipação do imazaquin, verificaram que no preparo de solo com arado o herbicida teve menor efeito residual que no preparo com escarificador e, este, menos que no PD. Independentemente do sistema de preparo de solo empregado, esses autores detectaram o imazaquin até $18 \mathrm{~cm}$ de profundidade. No entanto, Seifert et al. (2001) não encontraram diferenças na degradação do imazaquin entre

Tabela 1 - Estande de plantas (plantas $\left.\mathrm{m}^{-2}\right)$, número de colmos $\left(\operatorname{colmos} \mathrm{m}^{-2}\right)$, altura de plantas $(\mathrm{cm})$, número de panículas $\left(\mathrm{m}^{-2}\right)$, esterilidade de espiguetas (\% esterilidade), número de grãos por panícula (grãos/panícula), peso de mil grãos e produtividade de grãos ( $\mathrm{kg} \mathrm{ha}^{-1}$.) dos cultivares IRGA 422CL e IRGA 417, dos quatro experimentos comparativos analisados em forma conjunta

\begin{tabular}{|l|c|c|c|c|c|c|c|c|}
\hline \multicolumn{1}{|c|}{ Cultivar } & Plantas $\mathrm{m}^{-2}$ & Colmos $\mathrm{m}^{-2}$ & $\begin{array}{c}\text { Altura } \\
(\mathrm{cm})\end{array}$ & Panículas $\mathrm{m}^{-2}$ & \% esterilidade & $\begin{array}{c}\text { Grãos/ } \\
\text { panícula }\end{array}$ & $\begin{array}{c}\text { Peso (g) } \\
\text { mil grãos }\end{array}$ & $\begin{array}{c}\text { Produtividade } \\
\text { de grãos } \\
\left(\mathrm{kg} \mathrm{ha}^{-1}\right)\end{array}$ \\
\hline IRGA 422CL & 291 & 604 & 89 & 457 & 24 & 85 & 26,3 & 9.069 \\
IRGA 417 & 265 & 600 & 89 & 443 & 23 & 83 & 25,5 & 8.944 \\
\hline Média & 278 & 602 & 89 & 450 & 8,8 & 84 & 25,9 & 9.007 \\
CV(\%) & 17 & 12 & 3 & 14 & 17,3 & 16,9 & 5,5 & 9 \\
Significância & NS & NS & NS & NS & NS & NS & NS & NS \\
Locais x Cultivar & NS & NS & NS & NS & NS & NS & NS & NS \\
\hline
\end{tabular}

NS: não significativo, com probabilidade de erro $\mathrm{P} \leq 0,5$. 


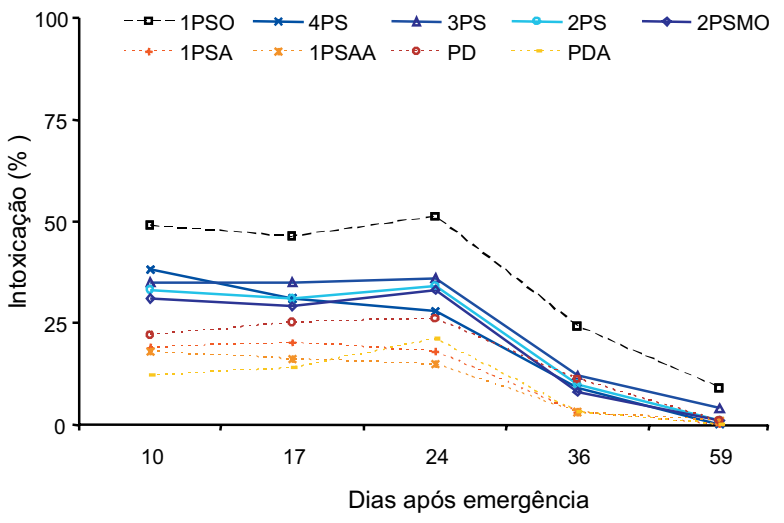

Figura 1 - Intoxicação do cultivar de arroz IRGA 417 causada pela mistura formulada de imazethapyr e imazapic $\left(75+25 \mathrm{~g} \mathrm{ha}^{-1}\right)$, semeada após um ano da última aplicação dos herbicidas, num sistema com dois anos de uso dos herbicidas, em cinco épocas de avaliação e nove preparos de solo: $\mathrm{PD}=$ plantio direto; $\mathrm{PDA}=$ plantio direto mais azevém; 1PSA = um preparo de solo (PS), em abril; 1PSAA = um PS em abril mais azevém; 1PSO = um PS, em outubro; $2 \mathrm{PSMO}=$ dois PS, em maio e outubro; $2 \mathrm{PS}=$ dois PS, em abril e outubro; $3 \mathrm{PS}$ = três PS, em abril, maio e outubro; 4PS = quatro PS, em abril, maio, agosto e outubro. Santa Maria-RS, 2006/07.

o preparo com arado e com escarificador. Ulbrich et al. (2005) observaram aumento na persistência de imazapic e imazapyr em dois solos com PD, comparado com o plantio convencional.

Ressalta-se que no presente trabalho, no sistema de plantio convencional, a profundidade de semeadura foi maior quando comparada com a dos sistemas de plantio direto e semidireto (6 e $2 \mathrm{~cm}$, respectivamente). A diferença na profundidade de semeadura foi consequência da impossibilidade de regular a pressão das molas da semeadora, para cada parcela com diferentes preparos de solo, ocasionando maior profundidade de semeadura onde o solo tinha sido preparado no mesmo dia da semeadura. A diferença na profundidade de semeadura possivelmente tenha sido a causa da maior introxicação nas plantas dos tratamentos que foram semeados mais profundamente. Segundo Zhang et al. (2000), quando uma plântula de arroz é originada de uma semente localizada em maior profundidade, apresenta coleóptilo mais comprido, o que acarreta maior área de contato com o solo, aumentando a absorção do imazethapyr e os sintomas de introxicação. Nesse sentido, esses autores não encontraram efeito residual de imazethapyr em arroz pré-germinado semeado em água sobre a superficie do solo e sim sobre plantas originadas de sementes semeadas em solo seco com máquina. Por outro lado, o tratamento 1PSO praticamente passou o mesmo período de tempo sem movimento de solo, quando comparado com os tratamentos com plantio direto (PD e PDA), razão pela qual a planta de arroz não deveria apresentar diferenças nos niveis de introxicação.

Para detectar diferenças na atividade dos herbicidas nas duas profundidades de semeadura sobre a introxicação das plantas, foi realizado um bioensaio utilizando-se solo coletado nas áreas de $0-3$ e $3-6 \mathrm{~cm}$ e tomate como planta indicadora; constatou-se que houve menor atividade dos herbicidas na camada superficial no tratamento 4PS do que no PD, em decorrência da menor introxicação das plantas de tomate (Figura 2).

Tendo em vista os resultados, pode-se inferir que as diferenças de introxicação entre esses tratamentos estão relacionadas, pelo menos em parte, a um efeito de posicionamento da semente e estratificação do herbicida no perfil do solo, e não ao efeito dos preparos de solo na degradação dos herbicidas. Concordando com isso, McDowell et al. (1997) eHJourdan et al. (1998) concluíram que imazethapyr lixivia-se acumulando-se em camadas subsuperficiais de solo, e as sementes

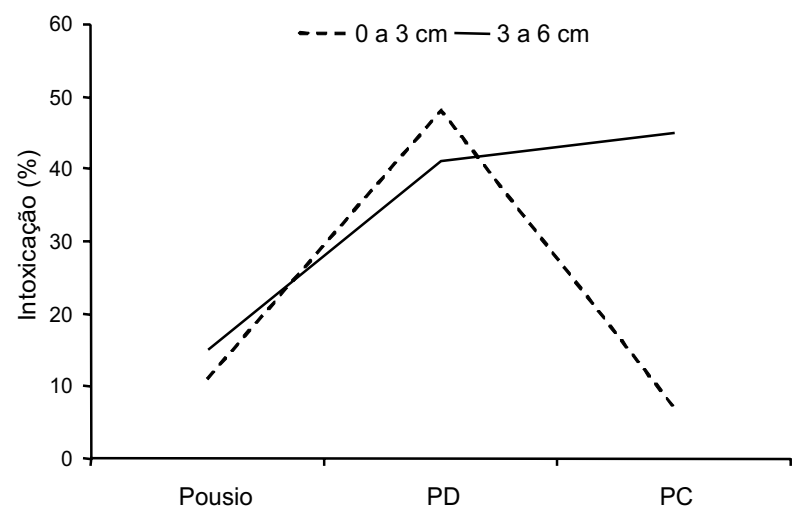

Figura 2 - Intoxicação em plantas de tomate semeadas sobre amostras de solo coletadas das parcelas dos tratamentos pousio (extraído de uma área deixada em pousio sem inundação), $\mathrm{PD}=$ plantio direto e 4PS = quatro preparos de solo, em abril, maio, agosto e outubro, em duas profundidades ( 0 a 3 e de 3 a $6 \mathrm{~cm})$. 
colocadas em maior profundidade estariam mais expostas a maiores concentrações de herbicidas.

Na Tabela 2 são apresentados os dados obtidos do efeito dos preparos de solo e do residual da mistura formulada de imazethapyr e imazapic sobre as variáveis agronômicas analisadas, nos cultivares IRGA 417 e IRGA 422CL. A interação significativa entre preparos de solo e cultivares, para estande de plantas e colmos $\mathrm{m}^{-2}$, foi causada por um menor número de plantas e de colmos no tratamento $1 \mathrm{PSO}$ no cultivar IRGA 417, o que não foi observado no cultivar IRGA 422CL, mantendo-se como efeito principal a diferença entre os cultivares (dados não apresentados). Por isso, serão discutidos os efeitos dos manejos do solo e dos cultivares em separado.

Os diferentes preparos de solo não alteraram o estande de plantas, o número de colmos, a altura de plantas, o número de panículas, o peso de mil grãos e a produtividade, concordando com resultados obtidos por Levy Jr. et al. (2006) e Tripathi et al. (2007), embora Mohanty et al. (2006) tenham afirmado que os preparos de solo, quando feitos em água, geram melhores condições físicas de solo para um melhor desenvolvimento do arroz.

Avaliando o efeito residual da mistura formulada de imazethapyr e imazapic no cultivar IRGA 417 em comparação com o cultivar
IRGA 422CL (tratamento testemunha), observou-se que o primeiro apresentou diminuição no estande de plantas, no número de perfilhos $\mathrm{m}^{-2}$, na altura de plantas, no número de panículas $\mathrm{m}^{-2}$, na esterilidade de espiguetas e na massa de mil grãos, porém obteve-se maior número de grãos por panícula. $\mathrm{O}$ maior número de grãos por panícula e a menor esterilidade de espiguetas, provavelmente, deveram-se a um efeito compensatório, ante um menor número de panículas $\mathrm{m}^{-2}$. $\mathrm{O}$ residual do herbicida não reduziu a produtividade, possivelmente como consequência do maior número de grãos por panículas; segundo Marín \& Kraemer (1999), com menor número de panículas, a planta de arroz apresenta incremento no número de grãos por panículas e menor esterilidade de espiguetas, como efeito compensatório da planta para manter a produtividade. Villa et al. (2006) observaram diminuição na densidade de plantas como resultado do efeito residual da mistura formulada de imazethapyr e imazapic, sem alterar a produtividade. No trabalho realizado por Santos et al. (2006), o efeito residual do herbicida alterou a produtividade em torno de $50 \%$. A menor recuperação da lavoura observada por Santos et al. (2006) provavelmente esteja relacionada, pelo menos em parte, ao menor pH do solo em relação ao deste trabalho: 4,5 e 4,8 , respectivamente. Essa pequena diferença no $\mathrm{pH}$ gera condições para que as moléculas de imazethapyr e imazapic encontrem-se

Tabela 2 - Estande de plantas de dois cultivares de arroz semeados em solo com nove sistemas de manejos, aos 10 e 17 dias após emergência (DAE), número de colmos $\left(\operatorname{colmos} \mathrm{m}^{-2}\right.$ ), altura de plantas $(\mathrm{cm})$, número de panículas (panículas $\left.\mathrm{m}^{-2}\right)$, esterilidade de espiguetas (\% esterilidade), número de grãos por panículas (grãos/panícula), peso de mil grãos (g) e produtividade de grãos $\left(\mathrm{kg} \mathrm{ha}^{-1}\right)$, em resposta ao efeito residual no solo de dois anos da mistura pronta de imazethapyr e imazapic. Santa Maria-RS. 2006/07

\begin{tabular}{|c|c|c|c|c|c|c|c|c|c|}
\hline \multirow{2}{*}{ Fonte de variação } & \multicolumn{2}{|c|}{ Plantas $\mathrm{m}^{-2}$} & \multirow{2}{*}{ Colmos $\mathrm{m}^{-2}$} & \multirow{2}{*}{$\begin{array}{l}\text { Altura } \\
(\mathrm{cm})\end{array}$} & \multirow{2}{*}{ Panículas $\mathrm{m}^{-2}$} & \multirow{2}{*}{$\%$ esterilidade } & \multirow{2}{*}{$\begin{array}{c}\text { Grãos/ } \\
\text { panícula }\end{array}$} & \multirow{2}{*}{$\begin{array}{l}\text { Peso }(\mathrm{g}) \\
\text { mil grãos }\end{array}$} & \multirow{2}{*}{$\begin{array}{c}\text { Produtividade } \\
\text { de grãos } \\
\left(\mathrm{kg} \mathrm{ha}^{-1}\right)\end{array}$} \\
\hline & $10 \mathrm{DAE}$ & $17 \mathrm{DAE}$ & & & & & & & \\
\hline Preparos do solo (PS) & 254 & 304 & 519 & 87 & 383 & 6,8 & 89 & 26,9 & 9.849 \\
\hline Significância ${ }^{2 /}$ & NS & NS & NS & NS & NS & NS & NS & NS & NS \\
\hline IRGA 422CL & $283 \mathrm{a}^{\mathrm{1}^{\prime}}$ & $350 \mathrm{a}$ & $599 \mathrm{a}$ & $88 \mathrm{a}$ & $404 \mathrm{a} 1$ & $8 \mathrm{a}$ & $85 \mathrm{~b}$ & $28 \mathrm{a}$ & 9.861 \\
\hline IRGA 417 & $226 \mathrm{~b}$ & $260 \mathrm{~b}$ & $440 \mathrm{~b}$ & $86 \mathrm{~b}$ & $361 \mathrm{~b}$ & $6 \mathrm{~b}$ & $93 \mathrm{a}$ & $26 \mathrm{~b}$ & 9.837 \\
\hline 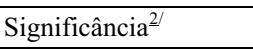 & $* * *$ & $* * *$ & $* * *$ & $*$ & $*$ & $*$ & $*$ & $* * *$ & NS \\
\hline PS x Cultivar & NS & $* * *$ & $* *$ & NS & NS & NS & NS & NS & NS \\
\hline $\mathrm{CV} \%$ & 17 & 18 & 21 & 4 & 18 & 4 & 18 & 5 & 11 \\
\hline
\end{tabular}

1/ Médias não seguidas pela mesma letra diferem significativamente entre si pelo teste de Tukey $(\mathrm{P} \leq 0,05)$.

2/ NS não significativa, $* * *$ significativa $(\mathrm{P} \leq 0,001)$, ** significativa $(\mathrm{P} \leq 0,01), *$ significativa $(\mathrm{P} \leq 0,05)$. 
20 e $11 \%$ associadas a $\mathrm{pH} 4,4$ e 4,8 , respectivamente, resultando praticamente no dobro de moléculas, no menor $\mathrm{pH}$, capaz de ser sorvido aos coloides do solo, aumentando assim a persistência do herbicida no solo. Segundo Bresnaham et al. (2000), a sorção do imazethapyr aumenta com $\mathrm{pH}$ mais baixo e após três meses a dessorção é maior nessas condições, causando maior introxicação em culturas suscetiveis.

Concluiu-se que para as condições de solo onde foi realizado este trabalho que o efeito residual da mistura formulada de imazethapyr e imazapic reduziu o estande de plantas, o perfilhamento, o número de panículas e a altura de plantas do cultivar não tolerante IRGA 417, sem alterar a produtividade de grãos. O revolvimento do solo diminuiu a atividade do herbicida na sua camada superficial $(0-3 \mathrm{~cm})$. Os diferentes sistemas de manejos de solo avaliados não alteraram o comportamento agronômico: estande de plantas, número de colmos, altura de plantas, número de panículas, esterilidade de espigueta, número de grãos por panícula, massa de grãos e produtividade.

\section{AGRADECIMENTOS}

Ao Instituto Nacional de Tecnologia Agropecuária - INTA Argentina e ao PPGA da Universidade Federal de Santa Maria (UFSM), pelo financiamento do trabalho.

\section{LITERATURA CITADA}

ALISTER, C.; KOGAN, M. Efficacy of imidazolinone herbicides applied to imidazolinone-resistant maize and their carryover effect on rotational crops. Crop Protect., v. 24, n. 4, p. $375-379,2005$.

ANGHINONI, I. et al. Fertilidade dos solos cultivados com arroz irrigado no Rio Grande do Sul. Cachoeirinha: IRGA, 2004. 52 p. (Boletim Técnico. 1).

BOVEY, R. W.; SENSEMAN, S. A. Response of food and forage crops to soil-applied imazapyr. Weed Sci., v. 46, n. 5, p. 614-617, 1998.

BRESNAHAM, G. A. et al. Influence of soil pH-sorption interactions on imazethapyr carry-over. Weed Sci., v. 48, n. 5, p. $1929-1934,2000$.

CROUGHAN, T. P. Herbicide resistent rice. Patent U.S., 5,773,704. 6-30-1998.
CURRAN, W. S. et al. Photolysis of imidazolinone herbicides in aqueous solution and soil, Weed Sci., v. 40, n. 1, p. $143-148,1992 \mathrm{a}$.

CURRAN, W.S. et al. Effect of tillage and application method on clomazone, imazaquin, and imazethapyr persistence.

Weed Sci., v. 40, n. 3, p. 482-489, 1992 b.

FERNANDES DE OLIVEIRA, M. et al. Sorção do herbicida imazaquin em Latossolo sob plantio direto e convencional. Pesq. Agropec. Bras., v. 39, n. 8, p. 787-793, 2004.

FLINT, J. L.; WITT, W. W. Microbial degradation of imazaquin and imazethapyr. Weed Sci., v. 45, n. 4, p. 586-591, 1997.

FRANCHINI, J. C. et al. Microbiological parameters as indicators of soil quality under various soil management and crop rotation systems in southern Brazil. Soil Tillage Res., v. 92, n. 1, p. 18-29, 2007.

JOURDAN, S. W. et al. Imazethapyr bioactivity and movement in soil. Weed Sci., v. 46, n. 5, p. 608-613, 1998.

LEVY Jr., R. J. et al. Effect of cultural practices on weed control and crop response in imidazolinone-tolerant rice. Weed Technol., v. 20, n. 1, p. 249-254, 2006.

LOPES, M. C. B. et al. Avaliação regionalizada de linhagens de arroz irrigado (Oryza sativa L.) no Rio Grande do Sul, Brasil, safra 2001/2002. In: INTERNATIONAL TEMPERATE RICE CONFERENCE, 3., 2003, Punta del Este. Abstracts... Punta del Este: Instituto Nacional de Investigación Agropecuaria, 2003. p. 35.

LOUX, M.; REESE, K. Effect of soil type and $\mathrm{pH}$ on persistence and carryover of imidazolinones herbicides. Weed Technol., v. 7, n. 2, p. 452-458, 1993.

MADANI, M. E. et al. pH effect and kinetic studies of the binding behaviour of imazethapyr herbicide on some Moroccan soils. Fres. Environ Bull., v. 1, n. 9, p. 1114-1119, 2003.

MARIN, A. R.; KRAEMER, A. F. Efecto de la densidad de plantas sobre el rendimiento de arroz. In: Proyecto Regional Arroz. Campaña 1997-1998. Corrientes: Estación Experimental Agropecuaria INTA Corrientes, p. 67-75, 1998.

McDOWELL, R. W. et al. Dissipation of imazapyr, flumetsulam and thifensulfuron in soil. Weed Res., v. 37, n. 6 p. 381-389, 1997.

MOHANTY, M. et al. Estimating impact of puddling, tillage and residue management on wheat (Triticum aestivum L.) seedling emergence and growth in a rice-wheat system using nonlinear regression models. Soil Tillage Res., v. 87, n. 1, p. 119-130, 2006.

Planta Daninha, Viçosa-MG, v. 27, n. 3, p. 581-588, 2009 
MONKS D. C.; BANKS P. A. Effect of straw, ash, and tillage on dissipation of imazaquin and imazetapyr. Weed Sci., v. 41, n. 3, p. 133-137, 1993

PEREZ, K. S. S. et al. Nitrogênio da biomassa microbiana em solo cultivado com soja, sob diferentes sistemas de manejo, nos Cerrados. Pesq. Agropec. Bras., v. 40, n. 2, p. 137-144, 2005

RENNER, K. A. et al. Effect of tillage and application method on corn (Zea mays) response to imidazolinone residues in soil. Weed Technol., v. 12, n. 2, p. 281-285, 1998.

SANTOS, F. M. et al. Alternativas de controle químico do arroz-vermelho e persistência dos herbicidas (imazethapyr + imazapic) e clomazone na água e no solo 2006. 72f. Dissertação (Mestrado em Agronomia) -

Universidade Federal de Santa Maria, Santa Maria, 2006

SEIFERT, S. et al. Imazaquin mobilityand persistence in a Sarkey Clay soil as influenced by tillage systems. Weed Sci., v. 49, n. 1, p. $571-577,2001$

SHANER, D. L.; O`CONNOR, S. The imidazolinones herbicides. Boca Raton: CRC Press, 1991.

SOON, Y. K.; ARSHAD, M. A. Tillage and liming effects on crop and labile soil nitrogen in an acid soil. Soil Tillage Res., v. 80, n. 1 , p. $23-33,2005$.
SOCIEDADE SUL-BRASILEIRA DE ARROZ IRRIGADO SOSBAI. Arroz irrigado: recomendações técnicas da pesquisa para o Sul do Brasil. Santa Maria: 2005. 159 p.

TAN, S. et al. Herbicidal inhibitors of amino acid biosynthesis and herbicide-tolerant crops. Amino Acids, v. 30 , n. 2 , p. $195-204,2006$

TRIPATHI, R. P. et al. Influence of tillage and crop residue on soil physical properties and yields of rice and wheat under shallow water table conditions. Soil Tillage Res., v. 92, n. 1/ 2, p. 221-226, 2007.

ULBRICH, A. V. et al., Persistence and carryover effect of imazapic and imazapyr in Brazilian croping systems. Weed Technol., v. 19, n. 4, p. 986-991, 2005.

VILLA, S. C. C. et al. Arroz tolerante a imidazolinonas: controle do arroz-vermelho, fluxo gênico e efeito residual do herbicida em culturas sucessoras não-tolerantes. Planta Daninha, v. 24, n. 4, p. 761-768, 2006.

WILLIAMS, B. J. et al. Weed management systems for clearfield rice. Louisiana Agric. Chemis., v. 45, n. 3 , p. 16-17, 2002.

ZHANG, W. et al. Effect of rotational crop herbicides on water- and dry-seeded Oryza sativa. Weed Sci., v. 48, n. 6, p. $755-760,2000$. 